\title{
EGFR alterations and EML4-ALK rearrangement in primary adenocarcinoma of the urinary bladder
}

Riley E Alexander ${ }^{1}$, Rodolfo Montironi ${ }^{2}$, Antonio Lopez-Beltran ${ }^{3}$, Sean R Williamson ${ }^{1}$, Mingsheng Wang ${ }^{1}$, Kristin M Post ${ }^{1}$, Joyashree D Sen ${ }^{1}$, Ashley K Arnold ${ }^{1}$, Shaobo Zhang ${ }^{1}$, Xiaoyan Wang ${ }^{1}$, Michael O Koch ${ }^{4}$, Noah M Hahn ${ }^{5}$, Timothy A Masterson ${ }^{4}$, Gregory T MacLennan ${ }^{6}$, Darrell D Davidson ${ }^{1}$, Eva Compérat ${ }^{7}$ and Liang Cheng ${ }^{1,4}$

${ }^{1}$ Department of Pathology and Laboratory Medicine, Indiana University School of Medicine, Indianapolis, IN, USA; ${ }^{2}$ Institute of Pathological Anatomy and Histopathology, School of Medicine, Polytechnic University of the Marche Region (Ancona), United Hospitals, Ancona, Italy; ${ }^{3}$ Department of Pathology, Cordoba University, Cordoba, Spain; ${ }^{4}$ Department of Urology, Indiana University School of Medicine, Indianapolis, IN, USA; ${ }^{5}$ Department of Internal Medicine, Indiana University School of Medicine, Indianapolis, IN, USA; ${ }^{6}$ Department of Pathology, Case Western Reserve University, Cleveland, OH, USA and ${ }^{7}$ Department of Pathology, Groupe Hospitalier Pitié-Salpêtrière, Paris, France

The identification of mutations in epidermal growth factor receptor (EGFR) and translocations involving anaplastic lymphoma kinase $(A L K)$ in lung adenocarcinoma has drastically changed understanding of the disease and led to the development of targeted therapies. Adenocarcinoma of the urinary bladder is rare and poorly understood at the molecular level. We undertook this study to determine whether EGFR mutations, increases in EGFR copy number, or ALK translocations are present in these tumors. Twenty-eight cases of primary bladder adenocarcinoma were analyzed. For EGFR mutational analysis, PCR-amplified products were analyzed on the Q24 Pyrosequencer with Qiagen EGFR Pyro Kits. All cases were analyzed via fluorescence in situ hybridization (FISH) using Vysis ALK Break Apart FISH Probes for detection of ALK chromosomal translocation and Vysis Dual Color Probes to assess for increased gene copy number of EGFR. None of the 28 cases examined showed mutational events in EGFR or ALK rearrangements. EGFR polysomy was seen in 10 out of $28(36 \%)$ cases. No correlation with EGFR polysomy was seen in the tumors with respect to age, histologic subtypes, pathologic stage, or lymph node metastasis. In summary, EGFR mutations and ALK rearrangements do not appear to be involved in the development of primary adenocarcinoma of the urinary bladder. A subgroup of cases (36\%), however, demonstrated increased gene copy number of EGFR by FISH. Modern Pathology (2014) 27, 107-112; doi:10.1038/modpathol.2013.132; published online 26 July 2013

Keywords: adenocarcinoma; EML4-ALK rearrangement; epidermal growth factor receptor (EGFR); gene copy number; polysomy; targeted therapy; urinary bladder

Approximately 356000 cases of urinary bladder cancer are diagnosed per year worldwide; however, primary adenocarcinoma accounts for less than $2 \%$ of these tumors. ${ }^{1-3}$ In some cases, primary adenocarcinoma has been associated with bladder exstrophy. ${ }^{4-6}$ Patients with primary urinary bladder

Correspondence: Dr L Cheng, MD, Department of Pathology and Laboratory Medicine, Indiana University School of Medicine, IU Health Pathology Laboratory Room 4010, 350 West 11th Street, Indianapolis, IN 46202, USA.

E-mail: liang_cheng@yahoo.com

Received 15 March 2013; revised 6 June 2013; accepted 6 June 2013; published online 26 July 2013 adenocarcinoma tend to present at a higher stage than those with urothelial carcinoma, although in some circumstances survival appears similar to or better than that of urothelial carcinoma. ${ }^{6,7}$ Histologically, tumors tend to demonstrate enteric morphology, closely resembling colonic adenocarcinoma. Therefore, care must be taken to exclude the possibility of secondary involvement of the urinary bladder in a primary colorectal tumor. ${ }^{8}$ The presence of signet-ring cell morphology is reported to portend a worse outcome. ${ }^{9,10}$ Radical surgery is the definitive treatment, although postoperative radiotherapy has been reported to enhance survival. ${ }^{4,5,11}$ Nonetheless, there is a need for better understanding 
of the pathogenesis of urinary bladder adenocarcinoma to guide more effective therapy.

Mutations in the epidermal growth factor receptor (EGFR) have been shown to be a driver mutation in tumorigenesis and cancer progression in many organs. ${ }^{12-15}$ Therapies targeting the mutant EGFR have allowed for new and more personalized treatment options in these cancers. ${ }^{16-18}$ Rearrangements involving anaplastic lymphoma kinase $(A L K)$, most notably the EML4-ALK rearrangement, have shown considerable clinical utility in the treatment of certain lung cancers. ${ }^{13,17,19-21}$ Although currently less specific and less predictive of therapeutic results, the detection of EGFR polysomy has been seen in many tumors to correlate with tumor activity and infers a role of EGFR in the propagation of tumors. ${ }^{22-25}$ The goal of this study was to determine whether EGFR mutations, EGFR polysomy, or $A L K$ rearrangements are present in primary adenocarcinoma of the urinary bladder as they may provide therapeutic targets in this disease.

\section{Materials and methods}

\section{Cases}

Twenty-eight patients with adenocarcinoma of the urinary tract (urinary bladder and urachus) were identified from the surgical pathology case files of the participating institutions (Figures 1a-d). The hematoxylin and eosin (H\&E) slides of each case, along with clinical histories, were reviewed to confirm diagnosis and primary tumor origin within the urinary bladder. Clinicopathologic information was also gathered via medical chart review.

\section{EGFR Mutational Analysis}

DNA extraction from formalin-fixed, paraffin-embedded (FFPE) tissue samples was performed using the Qiagen QIAamp DNA FFPE Tissue Kit (Qiagen, Valencia, CA, USA). DNA concentration was determined using the NanoDrop Spectrophotometer and adjusted to approximately $10 \mathrm{ng} / \mu \mathrm{l}$ in $\mathrm{dH}_{2} \mathrm{O}$. For EGFR mutational analysis, PCR-amplified products were analyzed on the Q24 Pyrosequencer with Qiagen EGFR Pyro Kits (Qiagen, Valencia, CA, USA). The pyrosequencing kit tests for mutations in the exon 18 codon 719 region, deletions in exon 19, mutations in the exon 20 codon 768 and codon 790 regions, and mutations in exon 21 codon regions 858-861. Resulting amplicons were purified, denatured, and sequenced using mutation-adjacent primers. Pyrograms were generated by software and interpreted for the presence of mutations in the corresponding codons.

\section{Fluorescence In Situ Hybridization}

Fluorescence in situ hybridization (FISH) studies were performed on $4-\mu$ m-thick paraffin sections.
Briefly, slides were deparaffinized with two 15-min washes in xylene and subsequently washed twice with $100 \%$ ethanol for $10 \mathrm{~min}$ each and air dried. The sections were heated at $95{ }^{\circ} \mathrm{C}$ in $0.1 \mathrm{mM}$ citric acid ( $\mathrm{pH}$ 6) solution (Invitrogen, Carlsbad, CA, USA) for $10 \mathrm{~min}$, rinsed with distilled water for $3 \mathrm{~min}$, and washed with $2 \times$ saline-sodium citrate (SSC) for $5 \mathrm{~min}$. Tissue digestion was performed by applying $0.4 \mathrm{ml}$ of pepsin (Sigma, St Louis, MO, USA) solution $(4 \mathrm{mg} / \mathrm{ml}$ in $0.9 \% \mathrm{NaCl}$ in $0.01 \mathrm{~N} \mathrm{HCl})$ to each slide and incubating the slides in a humidified box for $40 \mathrm{~min}$ at $37^{\circ} \mathrm{C}$. The slides were rinsed with distilled water for $5 \mathrm{~min}$, washed with $2 \times$ SSC for $5 \mathrm{~min}$, and then air dried.

EGFR alterations were detected by using LSI EGFR/CEP7 Dual Color Probe containing a centromeric probe for chromosome 7 (CEP7, spectrum green) and an EGFR probe located at 7p12 (EGFR, spectrum orange) (Vysis, Downers Grove, IL, USA). ${ }^{24-26} A L K$ gene rearrangement was detected using dual-color Vysis LSI ALK Break Apart Rearrangement Probe Kit (Vysis, Downers Grove, IL, USA). Five microliters of diluted probe was applied to each slide; coverslips were placed over the slides and sealed with rubber cement. The slides were denatured at $80^{\circ} \mathrm{C}$ for $10 \mathrm{~min}$ and hybridized at $37^{\circ} \mathrm{C}$ overnight. The coverslips were removed, and the slides were extensively washed with two $0.1 \times$ $\mathrm{SSC} / 1.5 \mathrm{M}$ urea solutions at $45^{\circ} \mathrm{C}$ for $20 \mathrm{~min}$, in $2 \times$ SSC at $45^{\circ} \mathrm{C}$ for $10 \mathrm{~min}$, and then in $2 \times \mathrm{SSC} / 0.1 \%$ $\mathrm{NP} 40$ at $45^{\circ} \mathrm{C}$ for $10 \mathrm{~min}$. Finally, the slides were washed with $2 \times$ SSC at room temperature for $5 \mathrm{~min}$, air dried, counterstained with $10 \mu \mathrm{l}$ DAPI/Antifade (DAPI in Fluorguard, $0.5 \mathrm{~g} / \mathrm{ml}$, Insitus), and sealed with nail polish.

The hybridized slides were observed and documented using a MetaSystem system (Belmont, MA, USA) under a $\times 100$ oil objective. The images were acquired with a CCD camera and analyzed with MetaSystem Isis software (Belmont, MA, USA). The following filters were used: SP-100 for DAPI, FITC MF-101 for spectrum green, and Gold 31003 for spectrum orange signals. Signals from each color channel (probe) were counted under pseudo color, with computerized translation of each color channel into blue, green, and red. Four sequential focus stacks with $0.3 \mu \mathrm{m}$ intervals were acquired and integrated into a single image to reduce thicknessrelated artifacts. A minimum of 100 nonoverlapping cancer cells were evaluated for each case, totaling 100-200 cells per case. Only if $\geq 90 \%$ of cells demonstrated sufficient signal was the slide considered to be qualified for counting.

The criteria for the EGFR FISH enumeration were adapted from Varella-Garcia et $a l^{27}$ and recommend criteria of FDA-approved PathVysion HER-2 DNA Probe Kit (package insert; Abbott Molecular, Des Plaines, IL, USA; January 2010). The criteria for the ALK FISH enumeration were according to the recommended criteria of FDA-approved Vysis ALK Break Apart FISH Probe Kit (package insert; Abbott 
a
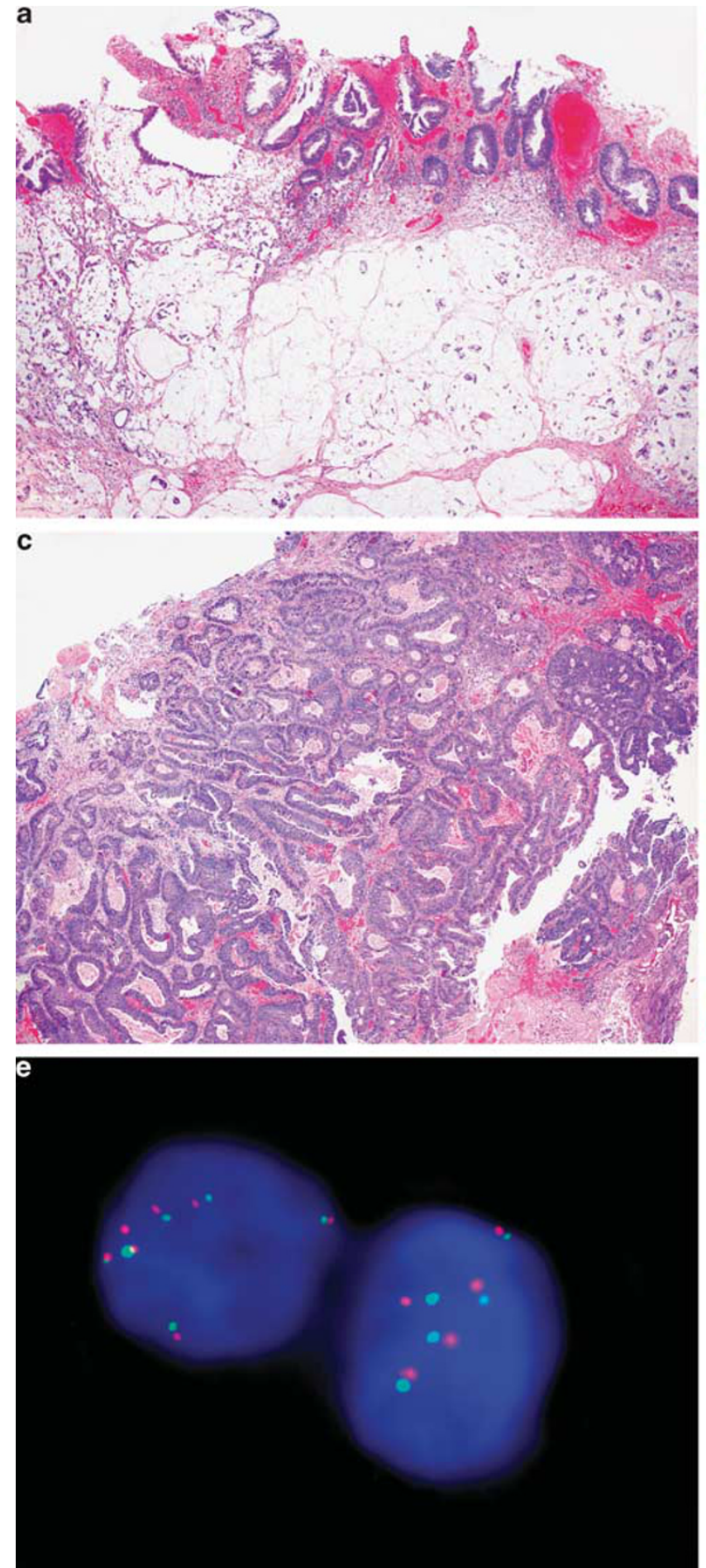
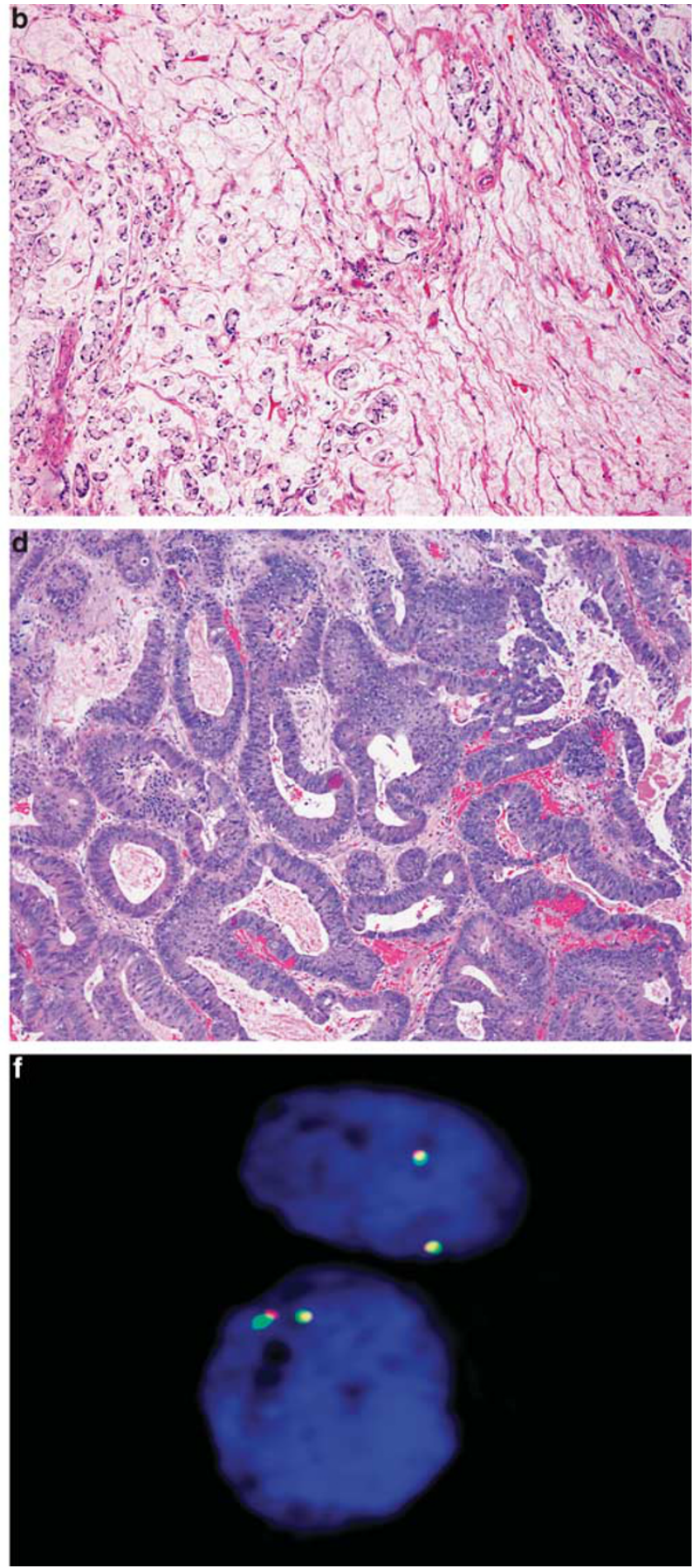

Figure 1 Morphology and interphase FISH for EGFR copy number and $A L K$ gene rearrangement in primary adenocarcinoma of the urinary bladder. (a) H\&E-stained section of primary adenocarcinoma of the urinary bladder. The tumor infiltrates the lamina propria with extravasation of mucin. (b) Adenocarcinoma composed of signet-ring cells infiltrating the bladder wall. (c) Enteric-type adenocarcinoma forming irregularly shaped cribriform glandular structures. (d) Higher magnification demonstrates a close resemblance to colorectal adenocarcinoma. (e) EGFR polysomy as detected by interphase FISH using LSI EGFR/CEP7 Dual Color Probe containing centromeric chromosome 7 (spectrum green) and EGFR probes (EGFR, spectrum orange). The cells showed EGFR polysomy as revealed by $>2$ copies per cell of signal pairs with red/green (EGFR/CEP7) signal ratio <2. (f) ALK alteration testing with $A L K$ break-apart probes. The $A L K$ gene showed a wild-type pattern as evidenced by fused red ( $3^{\prime}$ of $\left.A L K\right)$ and green ( $5^{\prime}$ of $\left.A L K\right)$ signals. 
Molecular, Des Plaines, IL, USA; August 2011) and Camidge et al. ${ }^{28}$ Briefly, EGFR amplification was considered to be present if $\geq 10 \%$ of the nuclei contained multiple EGFR signals and the EGFR/ CEP7 ratio was $\geq 2$. Polysomy for an individual tumor was defined as follows: $\geq 10 \%$ of the nuclei contained $>2$ signals of CEP7 or EGFR and the EGFR/CEP7 ratio was $<2$. For $A L K$, two fused or closely approximated red and green signals were considered the wild-type pattern. FISH was considered to be negative for $A L K$ rearrangement if $<5$ cells out of 50 or $<10 \%$ of cells demonstrated split red and green signals. $A L K$ fusion was interpreted as present if red and green signals were separated by a distance $>1.5$ signal diameters or single red signals were identified in $>25$ cells out of 50 or $>50 \%$ of cells show split signals. If the average percentage of positive cells from two separate readers was $\geq 15 \%$ $(\geq 15 / 100$ ), the sample was considered to be positive. These parameters are consistent with methods used in studies examining both EGFR and $A L K$ in lung adenocarcinoma. ${ }^{13,27-29}$

\section{Statistical Analysis}

Statistical analyses were performed using SPSS (Chicago, IL, USA). Fisher exact test was used to analyze association between genetic alterations. Statistical significance was defined as $P<0.05$, and all $P$-values were two sided.

\section{Results}

The average age of the patients in the series was 62 years, with a range of $32-87$ years. The male-tofemale ratio was 1.6:1. Of the studied cases, 9 out of the $28(32 \%)$ cases were from either transurethral resection or biopsy specimens. Of these cases, the majority (six out of nine, $67 \%$ ) were pT1 at the time of diagnosis. Of the 19 cystectomy or partial cystectomy specimens, $13(68 \%)$ cases were either pT3 or pT4 at the time of resection. Seven patients had lymph node metastasis, and two had distant metastases. The enteric-type pattern was the most common histology, present in $20(71 \%)$ of cases as either the sole or a constituent histologic pattern. Other patterns included mucinous, signet-ring cells and adenocarcinoma with neuroendocrine features.

In all 28 cases, EGFR mutational events were not identified by PCR methods. Using FISH to detect EGFR gains, polysomy was seen in 10 out of 28 $(36 \%)$ cases (Figure 1e), although EGFR amplification was not observed. Of the cases with EGFR polysomies, no distinct statistically significant correlation was seen with regard to age, sex, pathologic stage, or lymph node metastasis (all $P$-values were $>0.05$ ). It was observed that 3 out of the 10 cases with EGFR polysomy were found to be pT4 at the time of diagnosis (representing half of all pT4 cases). Seven cases had lymph node metastases, one of which had EGFR polysomy. In cases with increased EGFR copy number, enteric-type histology was present in 9 out of the 10 cases but was not statistically significant $(P=0.19)$. $A L K$ translocations were not identified in any of the 28 cases (Figure 1f).

\section{Discussion}

The detection of driving mutations within tumors that allow for prediction of targeted therapeutic benefits has radically changed the outlook and future goals of cancer treatment. As targeted therapies to these mutational events already exist, we sought to determine whether similar mutations were present in adenocarcinoma of the urinary bladder. Our results show that no identifiable mutations were seen in the analyzed domains of EGFR, nor were rearrangements involving $A L K$ present by FISH. We did, however, find EGFR polysomies in 10 tumors (36\%), indicating an increase in EGFR copy number. Polysomy status did not correlate with age, histologic subtype, pathologic stage, or lymph node metastasis. Enteric-type histology closely resembling colonic adenocarcinoma was the most common manifestation of primary urinary bladder adenocarcinoma (71\%). Most presented at a high pathologic stage (pT3 or pT4), particularly when definitive resection was performed and accurate pathologic staging could be determined. Ninety percent of cases with identified EGFR polysomy were enteric type.

The detection of EGFR polysomy (increased gene copy number) has been reported in a wide range of tumors, including lung adenocarcinoma, colonic adenocarcinoma, squamous-cell carcinoma of the vulva and head and neck, clear-cell renalcell carcinoma, sinonasal adenocarcinoma, and glioblastoma. . $^{3,6,12,15,22,23,30-33}$ In both the lung and the colon, some authors have reported a correlation with the presence of increased EGFR copy number and response to EGFR tyrosine kinase inhibitors and anti-EGFR monoclonal antibodies, respectively. Others have found conflicting results and, therefore, current recommendations for lung adenocarcinoma favor mutational testing over EGFR polysomy. ${ }^{15,23}$ This conflicting data and limited evidence showing a predictive nature to EGFR polysomy have limited its clinical utilization in these tumors. Further investigation is warranted.

Although this study analyzes the presence of molecular alterations in EGFR or ALK translocations, it does not serve to fully evaluate the entire spectrum of possible molecular alterations contributing to the tumorigenesis of primary bladder adenocarcinoma. Despite analyzing EGFR mutational events via PCR and EGFR polysomy by FISH, other alterations in EGFR have been reported that are not detected by these methods. The most widely reported of these alterations is the EGFRvIII mutation. ${ }^{13,17}$ However, the mutational events tested 
in this study are those most strongly associated with prediction to targeted therapies in lung adenocarcinoma and, as such, were the only ones examined. ${ }^{13,34}$ In addition, we chose to not evaluate EGFR expression by immunohistochemistry. This has been reported to be a poor predictor of response to therapy in lung adenocarcinoma and is seen to lack correlation with EGFR mutations. ${ }^{35,36}$ Prior studies performed at our institution have also shown that a poor correlation between EGFR polysomy and overexpression of EGFR is present in the prostate and germ cell tumors. ${ }^{24-26}$

As these results indicate that EGFR and $A L K$ do not play a significant role in the development of primary bladder adenocarcinoma, other mutational events must be occurring to drive the development and propagation of these tumors. Little, however, has been done to explore the molecular landscape of this tumor. A previous study by our group demonstrated that KRAS mutations were present in $12 \%$ of cases examined. ${ }^{37}$ Additional genetic studies on the tumor are limited, but Kunze and Schlott ${ }^{38}$ have reported a high frequency of epigenetic alterations within primary urinary bladder adenocarcinoma. In particular, they described these tumors having a high degree of promoter methylation of the 14-3-3 sigma $(S F N)$ and $C A G E 1$ genes.

Significantly more studies have been performed exploring the genetic landscape of the much more commonly occurring urothelial carcinoma. ${ }^{39}$ Investigations of BRAF mutations in urothelial carcinoma have mostly shown these to be a rare event, although occurring in up to $7 \%$ of cases. ${ }^{40-42}$ In addition, mutations in TSC2, PIK3R1, PIK3CA, and FGFR3 have been reported in urothelial carcinoma. ${ }^{42,43}$ Mutations in these genes lead to effects on well-studied downstream pathways such as AKT, RAS, and mTOR. These mutations, however, have not been reported or studied in primary bladder adenocarcinoma. Skeldon et $a l^{44}$ have shown an increased risk of urothelial cancer in patients with Lynch syndrome. We are unaware of any studies examining a correlation with Lynch syndrome or defects in mismatch repair genes when relating to primary bladder adenocarcinoma. These mutations occurring in urothelial carcinoma provide initial targets for further investigation as similar genetic events may be a possibility. The use of high-throughput sequencing techniques, such as next-generation sequencing, may expedite the discovery of additional genetic alterations and possible therapeutic targets.

Our findings indicate that primary urinary bladder adenocarcinoma lacks mutations in EGFR and $A L K$ gene rearrangements. A significant minority of cases (36\%), however, demonstrated EGFR polysomy. With increasing evidence indicating that EGFR overexpression may be an indicator of treatment response, further studies are required to determine the possible clinical utility of EGFR as a therapeutic target in the setting of primary adenocarcinoma of the urinary bladder.

\section{Disclosure/conflict of interest}

The authors declare no conflict of interest.

\section{References}

1 Cheng L, Lopez-Beltran A, Bostwick DG. Bladder cancer: general features, In: Cheng L, Lopez-Beltran A, Bostwick DG (eds) Bladder Pathology. Wiley-Blackwell: Hoboken, NJ; 2012, pp 137-160.

2 Grignon DJ, Ro JY, Ayala AG, et al. Primary adenocarcinoma of the urinary bladder. A clinicopathologic analysis of 72 cases. Cancer 1991;67:2165-2172.

3 Ploeg M, Aben KK, Kiemeney LA. The present and future burden of urinary bladder cancer in the world. World J Urol 2009;27:289-293.

4 Kapur P, Lotan Y, King E, et al. Primary adenocarcinoma of the urinary bladder: value of cell cycle biomarkers. Am J Clin Pathol 2011;135:822-830.

5 Zaghloul MS, Nouh A, Nazmy M, et al. Long-term results of primary adenocarcinoma of the urinary bladder: a report on 192 patients. Urol Oncol 2006;24: 13-20.

6 Williamson SR, Lopez-Beltran A, Montironi R, et al. Glandular lesions of the urinary bladder:clinical significance and differential diagnosis. Histopathology 2011;58:811-834.

7 Ploeg M, Aben KK, Hulsbergen-van de Kaa CA, et al. Clinical epidemiology of nonurothelial bladder cancer: analysis of the Netherlands Cancer Registry. J Urol 2010;183:915-920.

8 Rao Q, Williamson SR, Lopez-Beltran A, et al. Distinguishing primary adenocarcinoma of the urinary bladder from secondary involvement by colorectal adenocarcinoma: extended immunohistochemical profiles emphasizing novel markers. Mod Pathol 2013;26: 725-732.

9 Del Sordo R, Bellezza G, Colella R, et al. Primary signet-ring cell carcinoma of the urinary bladder: a clinicopathologic and immunohistochemical study of 5 cases. Appl Immunohistochem Mol Morphol 2009; $17: 18-22$

10 Kunze E, Krassenkova I, Fayyazi A. Tumor-associated neoexpression of the pS2 peptide and MUC5AC mucin in primary adenocarcinomas and signet ring cell carcinomas of the urinary bladder. Histol Histopathol 2008;23:539-548.

11 Dahm P, Gschwend JE. Malignant non-urothelial neoplasms of the urinary bladder: a review. Eur Urol 2003;44:672-681.

12 Pao W, Girard N. New driver mutations in non-smallcell lung cancer. Lancet Oncol 2011;12:175-180.

13 Cheng L, Alexander RE, Maclennan GT, et al. Molecular pathology of lung cancer: key to personalized medicine. Mod Pathol 2012;25:347-369.

14 Okabe T, Okamoto I, Tamura K, et al. Differential constitutive activation of the epidermal growth factor receptor in non-small cell lung cancer cells bearing EGFR gene mutation and amplification. Cancer Res 2007;67:2046-2053.

15 Zhang S, Davidson DD, Montironi R, et al. Conceptual evoluation in cancer biology, In: Cheng L, Zhang D, Eble JN (eds) Molecular Genetic Pathology, Vol. 1, Springer: New York; 2013, pp 77-110.

16 Buettner R, Wolf J, Thomas RK. Lessons learned from lung cancer genomics: the emerging concept of 
individualized diagnostics and treatment. J Clin Oncol 2013;31:1858-1865.

17 Cheng L, Zhang S, Alexander R, et al. The landscape of EGFR pathways and personalized management of nonsmall-cell lung cancer. Future Oncol 2011;7:519-541.

18 Keedy VL, Temin S, Somerfield MR, et al. American Society of Clinical Oncology provisional clinical opinion: epidermal growth factor receptor (EGFR) mutation testing for patients with advanced nonsmall-cell lung cancer considering first-line EGFR tyrosine kinase inhibitor therapy. J Clin Oncol 2011; 29:2121-2127.

19 Horn L, Pao W. EML4-ALK: honing in on a new target in non-small-cell lung cancer. J Clin Oncol 2009;27:4232-4235.

20 Morris SW, Kirstein MN, Valentine MB, et al. Fusion of a kinase gene, ALK, to a nucleolar protein gene, NPM, in non-Hodgkin's lymphoma. Science 1994;263: 1281-1284.

21 Shaw AT, Yeap BY, Solomon BJ, et al. Effect of crizotinib on overall survival in patients with advanced non-small-cell lung cancer harbouring ALK gene rearrangement: a retrospective analysis. Lancet Oncol 2011;12:1004-1012.

22 Chung CH, Ely K, McGavran L, et al. Increased epidermal growth factor receptor gene copy number is associated with poor prognosis in head and neck squamous cell carcinomas. J Clin Oncol 2006;24:4170-4176.

23 Dahabreh IJ, Linardou H, Siannis F, et al. Somatic EGFR mutation and gene copy gain as predictive biomarkers for response to tyrosine kinase inhibitors in non-small cell lung cancer. Clin Cancer Res 2010;16:291-303.

24 Wang X, Zhang S, Maclennan GT, et al. Epidermal growth factor receptor protein expression and gene amplification in the chemorefractory metastatic embryonal carcinoma. Mod Pathol 2009;22:7-12.

25 Wang X, Zhang S, MacLennan GT, et al. Epidermal growth factor receptor protein expression and gene amplification in small cell carcinoma of the urinary bladder. Clin Cancer Res 2007;13:953-957.

26 Marks RA, Zhang S, Montironi R, et al. Epidermal growth factor receptor (EGFR) expression in prostatic adenocarcinoma after hormonal therapy: a fluorescence in situ hybridization and immunohistochemical analysis. Prostate 2008;68:919-923.

27 Varella-Garcia M, Diebold J, Eberhard DA, et al. EGFR fluorescence in situ hybridisation assay: guidelines for application to non-small-cell lung cancer. J Clin Pathol 2009;62:970-977.

28 Camidge DR, Kono SA, Flacco A, et al. Optimizing the detection of lung cancer patients harboring anaplastic lymphoma kinase (ALK) gene rearrangements potentially suitable for ALK inhibitor treatment. Clin Cancer Res 2010;16:5581-5590.

29 Lindeman NI, Cagle PT, Beasley MB, et al. Molecular testing guideline for selection of lung cancer patients for EGFR and ALK tyrosine kinase inhibitors: guideline from the College of American Pathologists, International Association for the Study of Lung Cancer, and Association for Molecular Pathology. Arch Pathol Lab Med 2013;137:828-860.

30 Eberhard DA, Johnson BE, Amler LC, et al. Mutations in the epidermal growth factor receptor and in KRAS are predictive and prognostic indicators in patients with non-small-cell lung cancer treated with chemotherapy alone and in combination with erlotinib. J Clin Oncol 2005;23:5900-5909.

31 Hirsch FR, Herbst RS, Olsen C, et al. Increased EGFR gene copy number detected by fluorescent in situ hybridization predicts outcome in non-small-cell lung cancer patients treated with cetuximab and chemotherapy. J Clin Oncol 2008;26:3351-3357.

32 Moroni M, Veronese S, Benvenuti S, et al. Gene copy number for epidermal growth factor receptor (EGFR) and clinical response to antiEGFR treatment in colorectal cancer: a cohort study. Lancet Oncol 2005;6:279-286.

33 Woelber L, Hess S, Bohlken H, et al. EGFR gene copy number increase in vulvar carcinomas is linked with poor clinical outcome. J Clin Pathol 2012;65:133-139.

34 Gandara DR, Grimminger P, Mack PC, et al. Association of epidermal growth factor receptor activating mutations with low ERCC1 gene expression in non-small cell lung cancer. J Thorac Oncol 2010;5: 1933-1938.

35 Wheeler DL, Dunn EF, Harari PM. Understanding resistance to EGFR inhibitors-impact on future treatment strategies. Nat Rev Clin Oncol 2010;7:493-507.

$36 \mathrm{Li}$ AR, Chitale D, Riely GJ, et al. EGFR mutations in lung adenocarcinomas: clinical testing experience and relationship to EGFR gene copy number and immunohistochemical expression. J Mol Diagn 2008;10: 242-248.

37 Alexander RE, Lopez-Beltran A, Montironi R, et al. KRAS mutation is present in a small subset of primary urinary bladder adenocarcinomas. Histopathology 2012;61:1036-1042.

38 Kunze E, Schlott T. High frequency of promoter methylation of the 14-3-3 sigma and CAGE-1 genes, but lack of hypermethylation of the caveolin-1 gene, in primary adenocarcinomas and signet ring cell carcinomas of the urinary bladder. Int J Mol Med 2007;20: $557-563$

39 Netto GJ, Cheng L. Molecular pathology of urinary bladder cancer, In: Cheng L, Eble JN (eds) Molecular Surgical Pathology. Springer: New York; 2013, pp 229-254.

40 Boulalas I, Zaravinos A, Delakas D, et al. Mutational analysis of the BRAF gene in transitional cell carcinoma of the bladder. Int J Biol Markers 2009;24:17-21.

41 Guo Y, Chekaluk Y, Zhang J, et al. TSC1 involvement in bladder cancer: diverse effects and therapeutic implications. J Pathol 2013;230:17-27.

42 Sjodahl G, Lauss M, Gudjonsson S, et al. A systematic study of gene mutations in urothelial carcinoma; inactivating mutations in TSC2 and PIK3R1. PLoS One 2011;6:e18583.

43 Juanpere N, Agell L, Lorenzo M, et al. Mutations in FGFR3 and PIK3CA, singly or combined with RAS and AKT1, are associated with AKT but not with MAPK pathway activation in urothelial bladder cancer. Hum Pathol 2012;43:1573-1582.

44 Skeldon SC, Semotiuk K, Aronson M, et al. Patients with Lynch syndrome mismatch repair gene mutations are at higher risk for not only upper tract urothelial cancer but also bladder cancer. Eur Urol 2013;63: 379-385. 